\title{
Vibratory Platform in the Tibial Bone Tissue of Wistar Rats Subjected to Immobilization
}

\author{
Pâmela da Silva, ${ }^{1}$ Maria Luiza Serradourada Wutzke, ${ }^{2}$ Morgana Neves, ${ }^{2}$ Lucineia de Fátima Chasko Ribeiro, ${ }^{3}$ Gladson Ricardo \\ Flor Bertolini ${ }^{3}$ \\ ${ }^{1}$ Academic of the course of Physiotherapy of the Universidade Estadual do Oeste do Paraná - Unioeste \\ 2.Master student of the Biosciences and Health program of Unioeste \\ 3.Professor of the graduation in physiotherapy
}

Disclose and conflicts of interest: none to be declared by all authors

\begin{abstract}
Introduction: immobilization is a common option for the treatment of orthopaedic disorders, such as sprains, ligament ruptures, muscle, joint and fracture injuries. But in addition to the beneficial effects, immobilization leads to movement restriction, which can affect bone and muscle composition. Several therapeutic measures have served to remobilization, in this sense, the vibratory platform is an equipment that can provide interesting results in remobilization. Thus, the present study was intended to evaluate the vibratory platform action in the tibial bone tissue of Wistar rats submitted to immobilization. The experimental model used 24 Wistar rats randomly divided into 4 experimental groups: G1 (control group), G2 (immobilized only), G3 (immobilization and free remobilization) and G4 (immobilization and remobilization with vibratory platform). Immobilization caused a reduction in the total area of immobilized bone, but did not produce differences in the area of the spinal canal. For the cortical bone thickness, all the immobilized groups presented a reduction compared to the control, but the group that had the treatment with the vibratory platform resembled the only group immobilized (G2). In the number of osteocytes, there was increase in G3 and G4 when compared to G1 and G2. The protocol of whole body vibration used in this study induced recovery of the cortical bone thickness, with no advantages for the other variables in relation to the free remobilization group.
\end{abstract}

Keywords: Immobilization; Vibration; Bone and bones.

\section{Introduction}

Bone tissue is extremely important for the human body, performing various functions such as protection, blood cell production, ion storage, as well as a base for insertion of tendons, muscles and ligaments, forming a system of levers for movement. ${ }^{1}$ However, its highly dynamic properties, are constantly changing in response to mechanical stimuli. ${ }^{2}$

Thus the mechanical stimuli generated by external forces can alter the properties of biological tissues as much as the lack of them, generating structural reactions in the bone. ${ }^{3}$ When in disuse, due to lack of weight bearing or of physical activity, a decrease in the necessary stimulus occurs for bone growth and remodeling, which may result in osteopenia and increase the possibility of fractures. ${ }^{4}$

Immobilization is often used in the treatment of orthopedic disorders, common in cases of sprains, ruptures of ligaments and tendons, muscle, joint and fracture injuries, helping to reduce pain, promoting the alignment of structures and enhancing the quality of life. However, the immobilization of limb precludes movement, which may affect bone and muscle composition ${ }^{5,6}$ There are also situations of immobilization due to inactivity or lack of tension stimuli such as bedridden patients and even astronauts in space missions exposed to microgravity, in which a metabolic imbalance occurs in the bone, generating a decrease in the bone mass and its functionality, thus making the bone susceptible to new lesions, such as recurrent fractures, which frequently appear, generating a need for effective rehabilitation protocols for these individuals to restore their functional capacity and quality of life. ${ }^{9}$

Among the therapeutic modalities indicated for musculoskeletal disorders, some options, such as pulsating electromagnetic field, low level laser therapy and whole-body vibration (WBV) have been studied in the physiotherapeutic field as a low risk alternative, which have shown positive results in the osteoporosis treatment. ${ }^{10}$ The vibratory platform produces sinusoidal oscillatory movements, this feature has been used to accelerate bone metabolism, increase bone mass and reduce the risk of fractures in people with osteoporosis ${ }^{11}$ in animal models it has been observed that WBV can accelerate the bone callus formation in the initial repair phase, promote mineralization and callus maturity in later phases, and still restore bone mechanical properties. ${ }^{12}$ Exposure to vibration occurs by the contact of the distal extremities of the body 
segments with the apparatus, which causes a vibratory propagation through various tissues before reaching muscles or bones, thus allowing a wider influence of vibration due to the favoring of its dissipation throughout the body. ${ }^{13}$

However, the use of WBV is recent and there are differences in the literature regarding the best parameters of use and effects. ${ }^{14-16}$ It is simply not known whether all the detrimental effects of immobilization can be reversed with remobilization techniques. Thus, studies that evaluate techniques for the functional and morphological recovery of bone, reestablishing its characteristics closer to normal, become interesting. The objective of the present study was to analyze the morphological and histomorphometric effects of the vibration platform remobilization in the tibial bone tissue of Wistars rats submitted to previous immobilization.

\section{Materials and Methods}

\section{Sample}

The study used 24 male Wistar rats, 8 weeks old, average weight $267 \mathrm{~g}$, kept in a light-dark photoperiod of 12 hours, temperature between $22-24^{\circ} \mathrm{C}$ and hygiene control with food and water ad libitum. After acclimation of one week, the animals were randomly divided into 4 experimental groups, with 6 rats in each group: G1 (control group, euthanasiated after 30 days of experiment), G2 (immobilized during 15 days and euthanized), G3 (after the period of immobilization, remained 15 days in free remobilization in the cage) and G4 (immobilization and remobilization with platform vibration). This project was approved by the Ethics Committee in Animals Use (CEUA) of the Universidade Estadual do Oeste do Paraná (UNIOESTE).

\section{Immobilization}

In order to carry out the immobilization, the animals were anesthetized (xylazine $15 \mathrm{mg} / \mathrm{kg}$ and ketamine $80 \mathrm{mg} / \mathrm{kg}$, intraperitoneally) and immobilized with a material suitable for to plaster (tissue dressing saturated with calcium sulphate dehydrated) in the form of powder white, featuring a plastered bandage.

Immobilized experimental groups had the immobilization molded from the abdominal region, just below the last ribs, to the right pelvis of each animal, being placed throughout the limb so that it remained in extension of the knee joint and full ankle plantar flexion. The animals were kept in this position for a period of 15 consecutive days. ${ }^{9}$

\section{WBV}

After 15 days of immobilization, the removal of the immobilization was done, and on the 16th day the remobilization protocol was started, being the free remobilization for G3 and remobilization on the Vibrooscillatory Arktus triplanar professional commercial platform, with a frequency of $60 \mathrm{~Hz}$ and vibrations with an amplitude of $2 \mathrm{~mm}$ for $\mathrm{G} 4 .{ }^{17} \mathrm{G} 4$ rats were contained in the platform by a device, constructed in white MDF, with a total area of $25.4 \mathrm{~cm}^{2}$ subdivided into eight bays with 13 centimetres wide, 19 centimetres long and 25 centimetres high, with rotation of animals to each application, so that the same rat did not always remain in the same bay; the daily duration was 10 minutes, three days intercalated per week, completed after 2 consecutive weeks. G2 animals were euthanized immediately after removal of the immobilization apparatus.

\section{Histological Analysis}

After two weeks of remobilization, G3 and G4 animals were anesthetized and euthanized by guillotine decapitation. The right pelvic limb was dissected and the tibia collected, fixed at Metacarn for 24 hours, and then washed in distilled water and decalcified in 5\% trichloroacetic acid (TCA) for approximately 28 days. Samples underwent dehydration for 1 hour in $70 \%, 80 \%$ and $90 \%$ alcohol, $95 \%$ overnight, and $100 \%$ alcohol for 4 baths of 1 hour each.

Then the material was diaphanized, impregnated and embedded in paraffin, the cross-cut blocks, with $7 \mu \mathrm{m}$ thickness in Olympus CUT 4055 microtome, and the blades stained with hematoxylin and eosin; two slides were prepared for each animal, with 3 sections for each, then the best cut was selected for photomicrography in a light microscope $\left(\right.$ Olympus $\left.{ }^{\circledR}\right)$.

The slides were photomicrographs with a final magnification of $4 \mathrm{X}$ for measuring the total bone area, and at 10X for the medullary canal area. Finally, a standardized quadrant was used, in 3 equidistant points in the transverse sections in the region of the tibia diaphysis, under the 20X increase to measure the mean cortical area thickness and the number of osteocytes. ${ }^{18}$ To perform such measurements and counts the Image Pro Plus $6.0^{\circledR}$ program was used.

\section{Statistical Analysis}

For statistical analysis the data were provided in mean and standard deviation, using Generalized Linear Models, with Sidak post-test, and the accepted level was $5 \%$. On the variables of canal area, thickness and cell count, the probability distribution used was Gamma and for the total area the distribution was Linear.

\section{Results}

Immobilization caused a reduction in the total area of immobilized bone (Wald $\mathrm{X}^{2}(3)=26.2 ; \mathrm{p}<0,001$ ). As to the area of the spinal canal there was no significant differences between the groups (Wald $\mathrm{X}^{2}(3)=2.4$; $p=0,494)$. For the thickness of the cortical bone there was a significant difference between G1 and the other groups, and also between G2 and G3, thus all immobilized groups presented a cortical canal reduction compared to the control, but the group 
that had the treatment with the platform similar to the immobilized group (G2) (Wald $\mathrm{X}^{2}(3)=43.2 ; \mathrm{p}<0,001$ ). As for the number of osteocytes, there was stepped up in G3 and G4 when compared to G1 and G2 (Wald $\left.\mathrm{X}^{2}(3)=34.3 ; \mathrm{p}<0,001\right)$ (table 1).

In the morphological analysis it was possible to observe a reduction in cortical bone thickness in G3 compared to the other groups (figure 1).

\section{Discussion}

The present study attempted to study the effects of WBV in the bone after a period of immobilization that produced changes in qualitative and quantitative variables of the bone. The mechanical stimulus on bone, such as the impact of exercises and pressures exerted on it, are fundamental for bone formation, and thus the decrease in the total area of immobilized

Table 1. Data expressed as mean \pm standard deviation for the morphometric variables of the bone tissue (total area ( $\mu \mathrm{m} 2)$, area of the medullary canal ( $\mu \mathrm{m} 2$ ), cortical bone thickness $(\mu \mathrm{m})$ and osteocyte count) for different groups (G1 control, G2 immobilized, G3 immobilized with free remobilization and G4 immobilized with remobilization in $\mathrm{PV}$ ).

\begin{tabular}{|c|c|c|c|c|}
\hline & G1 & G2 & G3 & G4 \\
\hline Total area & $\begin{array}{c}5859772.51 \pm \\
448172.34^{\mathrm{a}}\end{array}$ & $\begin{array}{c}4890830.87 \pm \\
493815.70^{b}\end{array}$ & $\begin{array}{l}4479689.71 \pm \\
608248.23^{b}\end{array}$ & $\begin{array}{c}4502443.86 \pm \\
760686.96^{b}\end{array}$ \\
\hline Medular canal area & $\begin{array}{c}2146030.33 \pm \\
285866.30^{\mathrm{a}}\end{array}$ & $\begin{array}{c}1952210.25 \pm \\
328780.61^{a}\end{array}$ & $\begin{array}{c}2068917.00 \pm \\
447643.21^{\mathrm{a}}\end{array}$ & $\begin{array}{c}1888904.14 \pm \\
350909.73^{a}\end{array}$ \\
\hline Thickness of cortical bone & $\begin{array}{c}491.83 \pm \\
56.71^{\mathrm{a}}\end{array}$ & $\begin{array}{c}412.62 \pm \\
71.25^{b}\end{array}$ & $\begin{array}{c}322.98 \pm \\
26.81^{c}\end{array}$ & $\begin{array}{c}390.59 \pm \\
36.56^{b}\end{array}$ \\
\hline Number of osteocytes & $\begin{array}{c}74.94 \pm \\
5.27^{a}\end{array}$ & $\begin{array}{c}75.79 \pm \\
9.71^{a}\end{array}$ & $\begin{array}{l}96.76 \pm \\
11.08^{b}\end{array}$ & $\begin{array}{l}96.81 \pm \\
15.27^{b}\end{array}$ \\
\hline
\end{tabular}

Equal letters demonstrate statistical similarity, while different letters show significant differences.

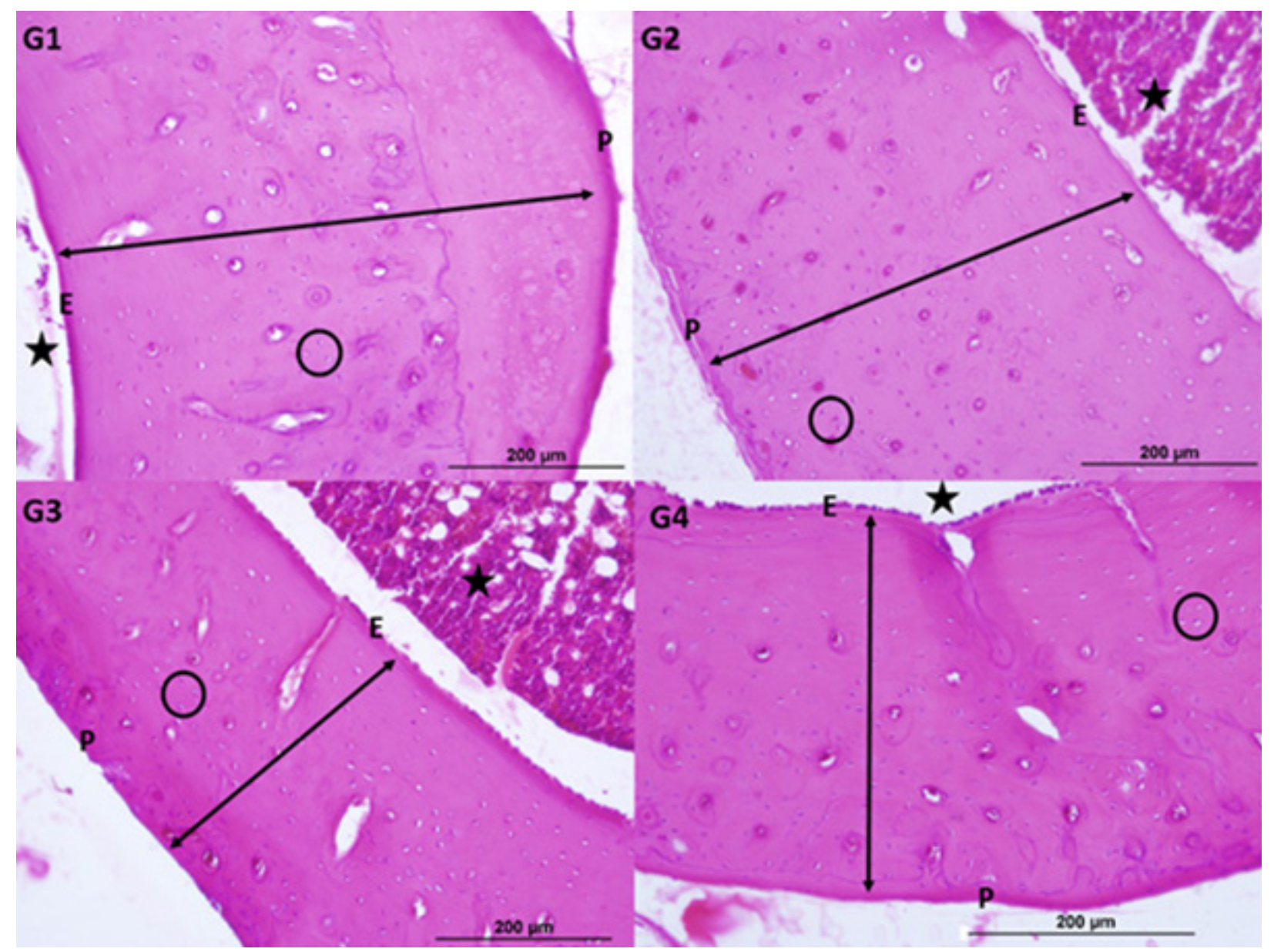

Figure 1. Photomicrograph of a cross-section of the tibial bone, stained at HE, with a 20x increase in the respective experimental groups G1, G2, G3 and G4. Stars represent the medullary canal, arrows represent the thickness of the cortical bone, within the circles are osteocyte cells, letters $P$ represents the periosteum and letters $\mathrm{E}$ represents the endosteum. 
bone, evidenced in this study, corroborates with the findings in the literature, since the lack of stimulus generated in immobilization, or disuse, leads to demineralization, ${ }^{7,8,19}$ reabsorption and decrease of bone density. ${ }^{20}$

However, immobilization did not cause changes in the area of the medullary canal, similar to those found in Santos et al. ${ }^{20}$ but in the present study the immobilized groups presented a significant reduction in the thickness of the cortical bone when compared to the control, since the total area also presented a decrease, it is presumed that there was a loss of bone mass from the periphery to the center of the bone. For these parameters, the vibratory platform group did not present a significant difference when compared to the only immobilized group, which presented the smallest reduction in cortical thickness, differing from G3 that presented a significant difference when compared to G2 in this way, the group that underwent WBV had smaller damage to its bone dimensions when compared to the group that performed the free remobilization, suggesting that during the remobilization time there is still bone loss, which is protected by the vibratory stimulus.

Sehmisch et al. ${ }^{21}$ studied the effects of vertical vibration of $90 \mathrm{~Hz}$ for 35 days in an animal model of osteoporosis induction, regarding quality and bone density, compared with a control group composed of osteoporotic animals without any intervention for treatment. The group that performed the vibratory platform showed a significant improvement in the biomechanical properties of the bone, an increase in bone density, especially in the trabecular bone, when compared to the cortical bone, showing an attractive treatment option for osteoporosis. On the other hand, Wuermser et al. ${ }^{15}$ using low amplitude WBV for six months, with a frequency of $34 \mathrm{~Hz}$, observed no changes in bone density and microstructure of paraplegic patients.

According to Judex et al. ${ }^{22}$ mechanical signals from vibration, if used as a correct frequency, can positively influence the bone by accelerating your metabolism. These authors examined the effects of vibration in the whole body, in frequencies of $45 \mathrm{~Hz}$ and $90 \mathrm{~Hz}$, applied for 10 minutes/day, in ovariectomized rats. After 28 days of treatment, the tibial bone formation of rats submitted to $90 \mathrm{~Hz}$ vibrations was $159 \%$ higher than that submitted to the $45 \mathrm{~Hz}$ frequency. However, Wang et al. ${ }^{14}$ in a systematic review point out that lower frequencies $(35$ and $50 \mathrm{~Hz}$ ) present better results with respect to the healing of fractures in oophorecomized rats, and also point to gains in neovascularization at the fracture site and in the surrounding muscles.
According to these studies, high frequencies and longer periods of treatment may be more effective in promoting an improvement in the recovery of bone tissue, contrary to what was used in this study, $60 \mathrm{~Hz}$ could not cause the bone characteristics returned to normal, but still the group submitted to remobilization in vibratory platform had better recovery when compared to the free remobilization group. However, according to Beck, ${ }^{23}$ lower frequencies $(20-50 \mathrm{~Hz}$, for 10-20 minutes) are the most indicated because they are safer and also to stimulate bone tissue, probably by direct action on the cytoskeleton and cell nucleus.

As for the number of osteocytes, both G3 and G4 showed a significant increase in their amount, indicating an increase in cellular activity in these groups that remained alive for another 15 days after the immobilization period. The mechanical stimulus, be it physical or electrical, through the mechanotransduction generates a cellular response that can be of bone production or resorption. Osteocytes are cells that induce and control bone remodeling, as they release biochemical mediators that govern the activity of osteoblasts and osteoclasts, which are more sensitive to mechanical stimulation than osteoblasts. ${ }^{24}$ Thus, the greater proliferation of osteocytes in both groups submitted to free remobilization and vibratory platform, shows that the mechanical stimulus in any way, generates an increase in remodeling cellular activity, helping to reverse the deleterious processes on the bone after a period of immobilization, which may indicate that with a longer period of time, this increased activity could produce effects of recovery of the other variables. According to Watson et al..$^{25}$ although the duration of a bone remodeling cycle is approximately 4 months, there is a degree of lag before a new bone mineralization can be observed, suggesting that the bone metabolism takes a longer time than 15 days to begin to act, which may indicate that the study period has not been sufficient to show major changes.

The WBV protocol used in this study induced additional effects on thickness of cortical bone in an animal model of immobilization when compared to the free remobilization group, but no advantages for the other variables analyzed. The vibratory platform has the potential to have beneficial results in rehabilitation, but more studies are needed to evaluate different frequencies and/or longer treatment periods.

\section{Acknowledgments}

To the Fundação Araucária for the scholarship of Scientific Initiation. 


\section{References}

1. Su N, Yang J, Xie Y, et al. Bone function, dysfunction and its role in diseases including critical illness. Int J Biol Sci. 2019;15(4):776-787. doi:10.7150/ijbs.27063.

2. Turner RT. What do we know about the effects of spaceflight on bone? J Appl Physiol. 2000;89(2):840-847.

3. Mueller MJ, Maluf KS. Tissue adaptation to physical stress: a proposed "Physical Stress Theory" to guide physical therapist practice. Phys Ther. 2002;82(4):383-403.

4. Esteves ACF, Bizarria FS, Coutinho MPG, Barreto TKDP, BrasileiroSantos $M$ do S, Moraes SRA de. A natação minimiza o retardo no crescimento somático e ósseo de ratos? Rev Bras Med do Esporte. 2010;16(5):368-372.

5. Vannabouathong C, Schemitsch E, Petrisor B, Bhandari $M$. Closed limb fractures with compromised vascularization: a narrative review. Clin Med Insights Arthiris Musculoskeltal Disord. 2019;12:1179544119836742. doi:10.1177/1179544119836742

6. Wang F, Zhang Q, Zhou Y, et al. The mechanisms and treatments of muscular pathological changes in immobilization-induced joint contracture: A literature review. Chinese J Traumatol. 2019;22(2):9398. doi:10.1016/j.cjtee.2019.02.001.

7. Khajuria DK, Razdan R, Mahapatra DR. Development, in vitro and in vivo characterization of zoledronic acid functionalized hydroxyapatite nanoparticle based formulation for treatment of osteoporosis in animal model. Eur J Pharm Sci. 2015;66:173-183. doi:10.1016/j.ejps.2014.10.015

8. Khajuria DK, Razdan R, Mahapatra DR. Additive effects of zoledronic acid and propranolol on bone density and biochemical markers of bone turnover in osteopenic ovariectomized rats. Rev Bras Ortop. 2015;55(2):103-112. doi:10.1016/j.rbre.2014.09.008.

9. Kunz RI, Silva LI, Roncini J, et al. Histomorphometric changes in the knee joint of Wistar rats after remobilization in a water enviroment. Fisioter e Pesqui. 2015;22(3):317-324. doi:10.590/18092950/14234922032015.

10. Alayat MSM, Abdel-Kafy EM, Thabet AAM, Abdel-Malek AS, Ali TH, Header EA. Long-term effect of pulsed Nd-YAG laser combined with exercise on bone mineral density in men with osteopenia or osteoporosis: 1 year of follow-up. Photomed Laser Surg. 2018;36(2):105-111. doi:10.1089/pho.2017.4328

11. Fernandes KR, Oliveira P de, Bertolo D, Andrade GN de, Matsuda NY, REnno ACM. Efeitos dos recursos eletrofísicos na osteoporose: uma revisão da literatura. Fisioter em Mov. 2010;23(2):271-281.

12. Chen J, Ruan H, Liu Y, et al. Therapeutic effects of whole-body vibration on fracture healing in ovariectomized rats: a systematic review and meta-analysis. Menopause. 2019;26(6):677-686. doi:10.1097/ GME.0000000000001285.
13. Batista MAB, Wallerstein LF, Dias RM, Silva RG, Ugrinowitsch C, Tricoli V. Efeitos do treinamento com plataformas vibratórias. Rev Bras Ciência Mov. 2007;15(3):103-113.

14. Wang J, Leung KS, Chow SKH, Cheung WH. The effect of whole body vibration on fracture healing - a systematic review. Eur Cells Mater. 2017;34:108-127. doi:10.22203/eCM.v034a08

15. Wuermser L, Beck LA, Lamb JL, Atkinson EJ, Amin S. The effect of lowmagnitude whole body vibration on bone density and microstructure in men and women with chronic motor complete paraplegia. J Spine Cord Med. 2015;38(2):178-186.

16. Peretti AL, Ciqueleiro RT, Flores LJF, Bertolini GRF. Use of wholebody vibration as osteoporosis treatment in postmenopausal women: a systematic review. Eur J Clin Exp Med. 2019;17(12):146-152. doi:10.15584/ejcem.2019.2.

17. Kakihata CMM, Peretti AL, Wutzke MLS, Tavares AL de F, Ribeiro $L$ de FC, Bertolini GRF. Morphological and nociceptive effects of mechanical vibration on the sciatic nerve of oophorectomized Wistar rats. Motriz. 2019;25(1):e101949.

18. Leite MOR, Batalha JR. Papel da histomorfometria óssea no diagnóstico diferencial da osteomalácia. Arq Bras Endocrinol Metabol. 2000;44(2):148-152.

19. Panisset MG, Galea MP, El-Ansary D. Does early exercise attenuate muscle atrophy or bone loss after spinal cord injury? Spinal Cord. 2016;54(2):84-92. doi:10.1038/sc.2015.150.

20. Santos JS dos, Kunz RI, Reis GH dos, et al. Histomorfometria do fêmur de ratos remobilizados por natação e salto em meio aquático. Varia Sci Ciências da Saúde. 2015;1(1):42-49.

21. Sehmisch S, Galal R, Kolios L, et al. Effects of low-magnitude, high-frequency mechanical stimulation in the rat osteopenia model. Ostoeporosis Int. 2009;20(12):1999-2008. doi:10.1007/s00198-0090892-3.

22. Judex S, Lei X, Han D, Rubin C. Low-magnitude mechanical signals that stimulate bone formation in the ovariectomized rat are dependent on the applied frequency but not on the strain magnitude. J Biomech. 2007;40(6):1333-1339. doi:10.1016/j.jbiomech.2006.05.014 23. Beck BR. Vibration therapy to prevent bone loss and falls: mechanisms and efficacy. Curr Osteoporos Rep. 2015;13(6):381-389. doi:10.1007/s11914-015-0294-8.

24. Gusmão CVB de, Belangero WD. Como a célula óssea reconhece o estímulo mecânico? Rev Bras Ortop. 2009;44(4):299-305.

25. Watson SL, Weeks BK, Weis LJ, Harding AT, Horan SA, Beck BR. High-intensity resistance and impact training improves bone mineral density and physical function in postmenopausal women with osteopenia and osteoporosis: the LIFTMOR randomized controlled trial. J Bone Miner Res. 2018;33(2):211-220. doi:10.1002/jbmr.3284.
Received: May 2, 2019

Accepted: March 27, 2021
Corresponding author

Gladson Ricardo Flor Bertolini

E-mail: gladsonricardo@gmail.com 